Article

\title{
Exergy and Thermoeconomic Analysis for an Underground Train Station Air-Conditioning Cooling System
}

\author{
Ke Yang Liao and Yew Khoy Chuah * \\ Department of Energy and Refrigerating Air-conditioning Engineering, National Taipei University \\ of Technology, 1, Sec. 3, Zhong Xiao E. Road, Taipei 10608, Taiwan; lkygm3793@gmail.com \\ * Correspondence: yhtsai@ntut.edu.tw; Tel.: +886-2-2771-2171 (ext. 3508); Fax: +886-2-8773-3713 \\ Academic Editor: Reiner Kümmel \\ Received: 25 November 2015; Accepted: 23 February 2016; Published: 7 March 2016
}

\begin{abstract}
The necessity of air-conditioning causes the enormous energy use of underground train stations. Exergy and thermoeconomic analysis is applied to the annual operation of the air-conditioning system of a large underground train station in Taiwan. The current installation and the monitored data are taken to be the base case, which is then compared to three different optimized designs. The total revenue requirement levelized cost rate and the total exergy destruction rate are used to evaluate the merits. The results show that the cost optimization objective would obtain a lower total revenue requirement levelized cost rate, but at the expense of a higher total exergy destruction rate. Optimization of thermodynamic efficiency, however, leads to a lower total exergy destruction rate, but would increase the total revenue requirement levelized cost rate significantly. It has been shown that multi-objective optimization would result in a small marginal increase in total revenue requirement levelized cost rate, but achieve a significantly lower total exergy destruction rate. Results in terms of the normalized total revenue requirement levelized cost rate and the normalized total exergy destruction rate are also presented. It has been shown by second law analysis when applied to underground train stations that lower annual energy use and lower $\mathrm{CO}_{2}$ emissions can be achieved.
\end{abstract}

Keywords: exergy; thermoeconomic analysis; air-conditioning system; underground train station

\section{Introduction}

The necessity of air-conditioning and also long operation hours is a major cause of the enormous amount of energy use for an underground train station. In this study, exergy and thermoeconomic analysis is applied to an underground train station that was constructed in Taiwan in recent years. The current status of the station is taken as the base case. Exergy indicates both the quality and the quantity in the energy conversion. Exergy destruction in reverse is the indicator of energy loss in terms of quality and quantity. Exergy is in fact indicative of thermodynamic second law efficiency. For the practical concerns of cost and economy, the total revenue requirement levelized cost rate can be used to evaluate the merit [1].

Some research literature can be found in the field of exergy and thermoeconomic analysis. However, only some is on the optimization of air-conditioning systems. Moreover, in some of the literature, only one of the exergetic or thermoeconomic criteria is considered. The exergetic criteria were discussed in many articles. Kodala et al. [2] studied the irreversibility of the thermoeconomic performance of refrigerators and heat pumps. Kodala et al. [3] investigated the thermoeconomic optimization of a two-stage combined heat pump system. Yumrutas et al. [4] performed exergy analysis on vapor compression refrigeration systems. Rezaie et al. [5] used exergy analysis for residential buildings' assessment. Lu et al. [6] studied the patterns of domestic energy consumption 
using exergy analysis. Marletta et al. [7] applied exergy analysis to assess different constructions of air-conditioning systems.

In the field of thermal systems, Yilmaz et al. [8] applied second law analysis to evaluate the performance of heat exchangers. Bejan [9] analyzed the optimized geometry of engineering flow in terms of thermodynamics. Bisio and Rubatto [10] studied different aspects of irreversible processes in closed and steady-state open systems. Chen et al. [11] studied the optimal performance of an irreversible absorption refrigerator. Wall and Gong [12] presented the concept of exergy in sustainable development. Abhilash et al. [13] applied exergy efficiency to evaluate the inlet air cooling system for a centrifugal compressor.

There are several studies on thermoeconomic criteria. Sciubba [14] presented the concept of extended exergy accounting for the design of thermal systems. Li et al. [15] studied the economic benefits of automated fault detection and diagnosis for rooftop air-conditioners. Sivasakthivel et al. [16] discussed the optimized operating parameters for ground source heat pump systems. Liu and Niu [17] developed an optimal design analysis for heat recovery devices in buildings. Piacentino and Talama [18] proposed an improved thermoeconomic approach to the increase the reliability of the refrigeration system. The above studies show that multi-objective optimization can be applied to deal with different and competing objectives.

Multi-objective optimization of energy systems has attracted some attention in the related fields of research in recent years. Multi-objective optimization was used by Sayyadi and Nejatolahi [19] for a cooling tower-assisted refrigeration system. The total revenue requirement method and the total exergy destruction of the system were applied in their study. Sayyadi and Nejatolahi [20] also carried out multi-objective optimization for a cooling tower-assisted ground source heat pump. Three optimized objectives were included in their study. Sun et al. [21] investigated the relationship between the economic cost and the reliability of city electric supply.

More published literature on multi-objective optimization can be found recently. Rosen [22] discussed the economic benefits of applying the concept of exergy. In the area of thermal systems, published literature on multi-objective optimization can be found for $\mathrm{CO}_{2} / \mathrm{NH}_{3}$ refrigeration, integrated molten carbonate fuel cells, the organic Rankine cycle, combined gas turbines and solar energy [23-27].

Performance models of chillers and pumps for air-conditioning systems can be found in the research literature [28-31]. For dynamic energy saving control, Ma et al. [32] presented a real-time supervisory control strategy for building cooling water systems.

In the area of increasing the energy efficiency of air-conditioning, Du et al. [33] present a control-perfect index based on exergy analysis. They use the index to evaluate the control of an air-conditioning system. A novel cascade air-conditioning system of a 100-kW capacity of a sample building was proposed by Hojjat Mohammadi and Ameri [34]. Zagoet et al. [35] analyzed different combinations of heating systems and evaluated the primary energy efficiency for residential buildings in northern Italy.

In summary, most of the research on exergy and thermoeconomic analysis for air-conditioning systems has been of simple systems and at fixed state conditions. However, for an underground station, the air-conditioning operation is dynamic, also with the variation in ambient temperature. The energy use would be enormous when the underground train station is situated in a subtropical region, like Taiwan. Design analysis to balance the construction cost and energy efficiency is of upmost importance. This study considers the operation and maintenance cost due to the selection of systems that were overlooked in most of the published literature. In this study, the objective functions are the total revenue requirement levelized cost rate of the system $\dot{C}_{T R R L}$ and the total exergy destruction rate $\dot{I}_{\text {tot }}$. The monitored operation of the present system was taken to be the base case, against different cases of optimization. The results presented are based on an actual underground train station. 


\section{Air-Conditioning System and Methods}

\subsection{The Underground Train Station and Its Air-Conditioning System}

The underground train station is located in Taipei, Taiwan, which began operation in 2011. The station building has dimensions of $330 \mathrm{~m}$ in length, $24 \mathrm{~m}$ in width and $21 \mathrm{~m}$ underground. The floor plan of the station includes the U-2F ( 2 floors underground) platform area, the U-1F (1 floor underground) concourse area, the $\mathrm{G}+1 \mathrm{~F}$ (ground level) lobby and retail and the $\mathrm{G}+2 \mathrm{~F}$ (second floor) retail store area. The $\mathrm{G}+2 \mathrm{~F}$ retail store area has a separate air-conditioning system and is metered separately; therefore, it was not included in this study. The floor plan of the station and the different zones served by a general and a $24-\mathrm{h}$ system are shown in Figure 1 . Zones enclosed by blue lines were served by the general system, and those enclosed by green lines were served by the $24-h$ system.

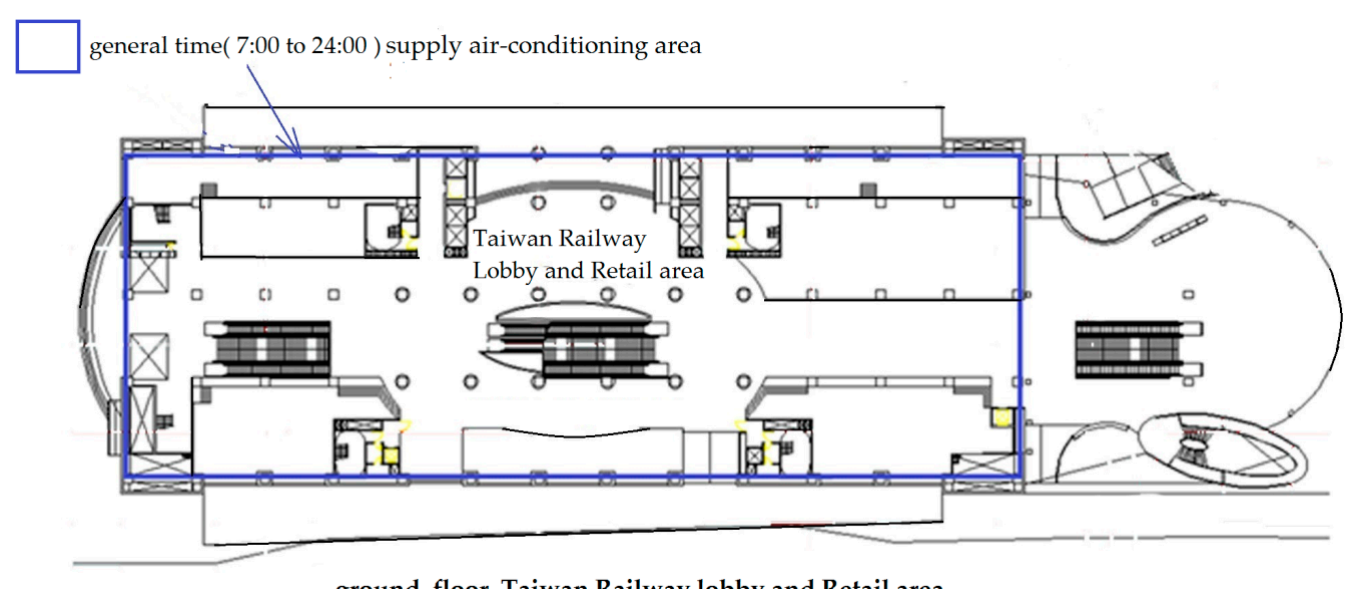

ground floor Taiwan Railway lobby and Retail area

(a)

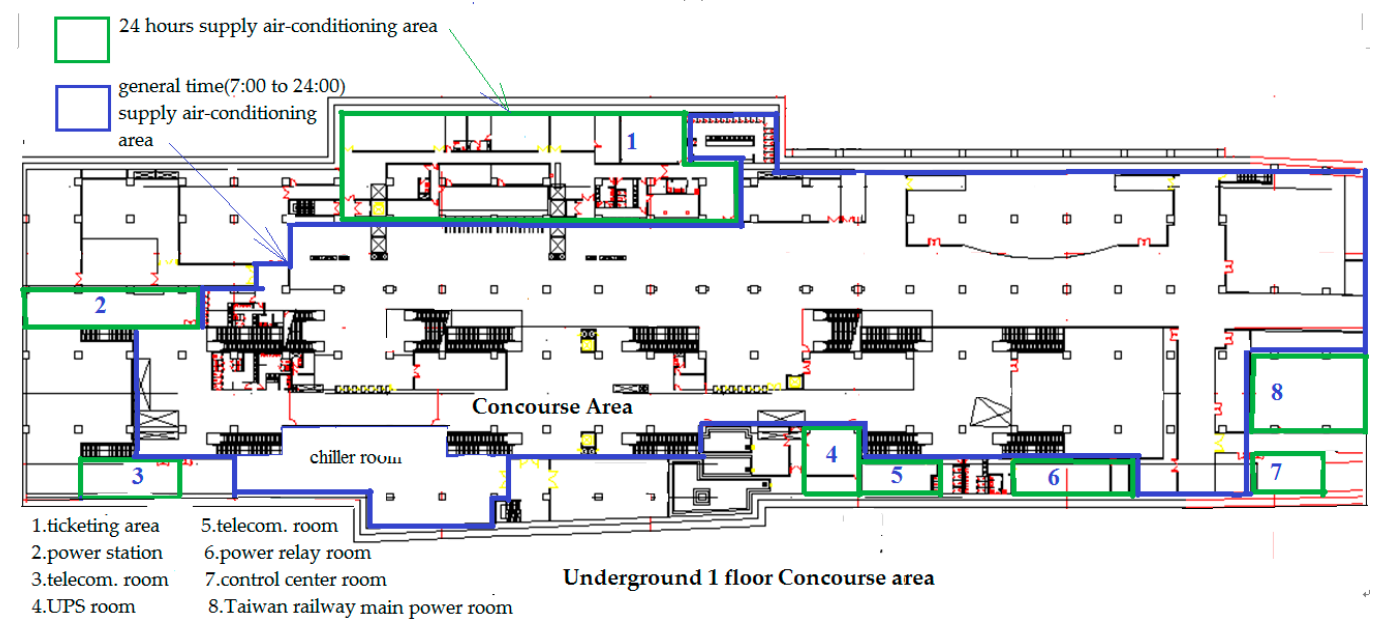

(b)

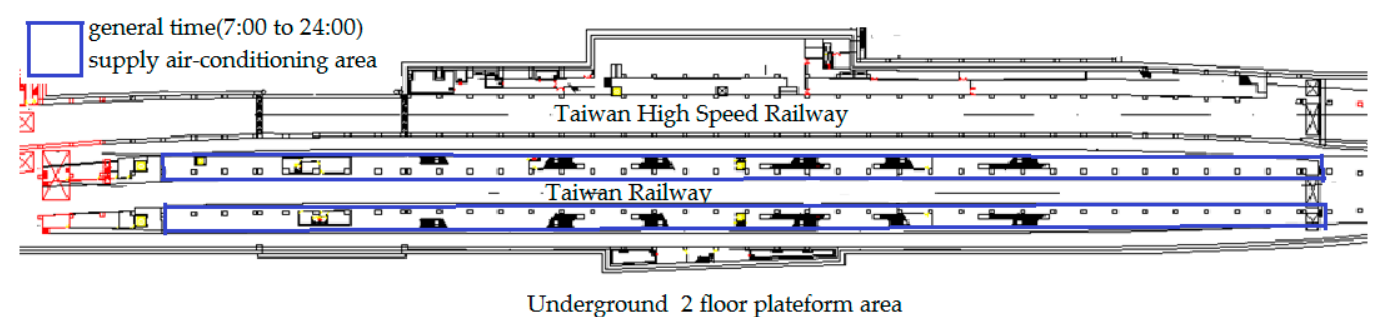

(c)

Figure 1. Station floor plan and zones served by a general and a 24-h AC system. (a) The ground floor plan; (b) the underground U-1 floor plan; (c) the underground U-2 floor plan. 
The 24-h air-conditioning system serves specific areas, including the central control room, the telecom room, the UPS room, the main power station, the power relay room and also the ticket area. The rest of the station is served by the general air-conditioning system, such as the $G+1 F$ lobby and retail area, the U-1F concourse area and the U-2F platform area, as shown in Figure 2.

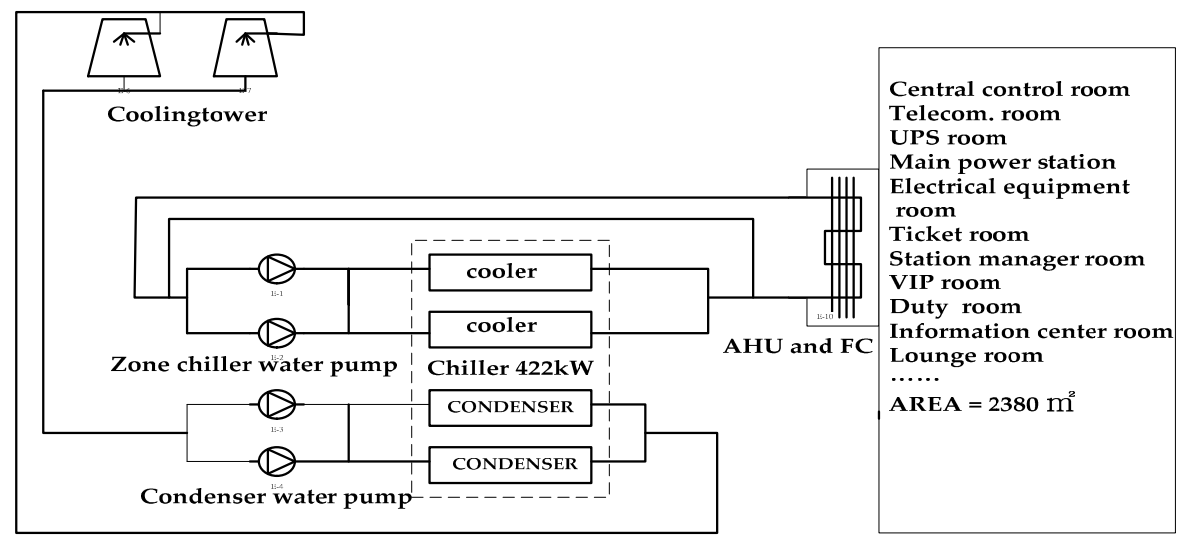

24 h supply air-conditioning system

(a)

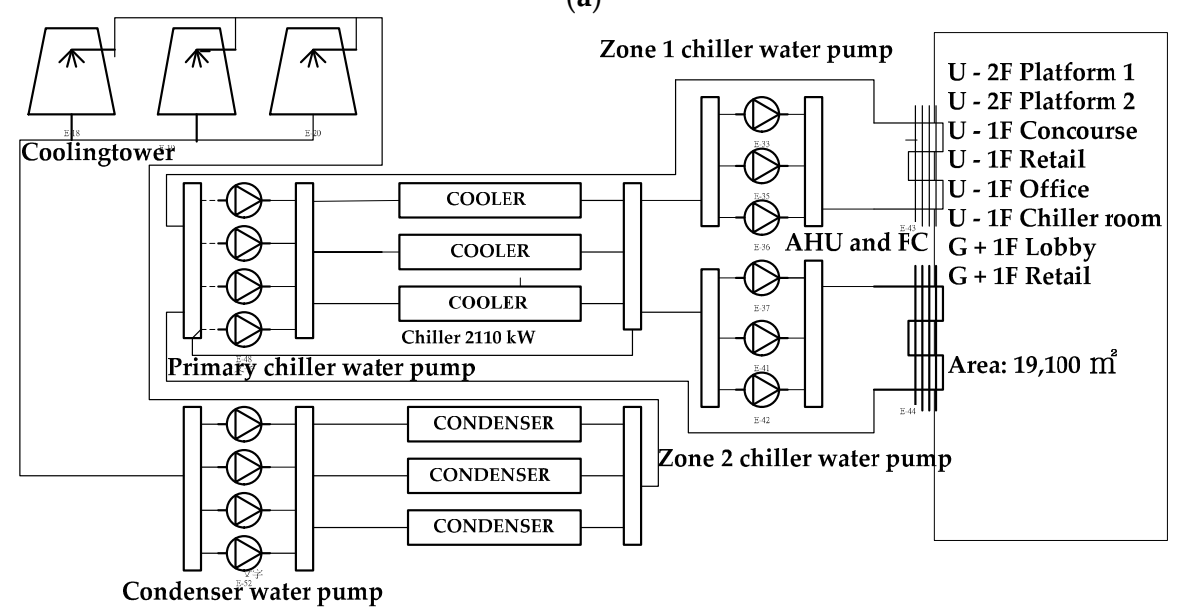

General time ( 7:00 h to 24:00 h ) supply Air-conditioning system

(b)

Figure 2. The schematics of the 24-h and the general air-conditioning systems. (a) The schematics of the 24-h air-conditioning system; (b) the schematics of the general air-conditioning system. AHU, air handling unit; FC, fan coils.

\subsection{Energy Exergy and Thermoeconomic Analysis}

The hourly monitored data used for the base case (BC) were collected from the building automation system (BAS), supplemented by information from the equipment suppliers, the Central Weather Bureau of Taiwan and also the local power company for the year 2012.

\subsubsection{Energy Analysis}

The cooling capacity $\dot{Q}(\mathrm{~kW})$ of a chiller can be calculated as:

$$
\dot{Q}=\dot{m}_{w e} c_{p}\left(T_{e i}-T_{e o}\right)
$$


In Equation (1), $\dot{m}_{w e}$ is the chilled water flowrate. $T_{e i}$ and $T_{e o}$ are the chilled water temperatures flowing in and out through the evaporator, respectively. The specific heat capacity of water $C_{P}=4.186 \mathrm{~kJ} \cdot \mathrm{kg}^{-1} \cdot \mathrm{K}^{-1}$. Figure 2 shows that there is more than one chiller for each system. The average coefficient of performance $C O P_{a v g}$ of the chillers for either the general or the 24-h systems can be calculated using Equation (2):

$$
C O P_{\text {avg }}=\sum_{1}^{j} \sum_{1}^{k}\left[\dot{m}_{w e, k j} c_{p}\left(T_{e i, k j}-T_{e o, k j}\right)\right] / \sum_{1}^{j} \sum_{1}^{k} \dot{W}_{a c, k j}
$$

In Equation (2), $k$ is the number of chillers, and $j$ is each of the operating hour in a year. $\dot{W}_{a c, k j}$ is the compressor of the acting chiller in the hour. In times of lower cooling demand, only one chiller would be operating.

The operating power $(\mathrm{kW})$ of a pump, either for a chilled water pump or a condensing water pump, can be calculated by using Equation (3):

$$
\dot{W}_{p u}=\frac{\dot{v} \Delta p}{\eta}
$$

where $\dot{v}$ is the volume flow rate $\mathrm{m}^{3} \cdot \mathrm{s}^{-1}$ and $\Delta p$ is the pressure jump (Pa) though the pump. The total power consumption of an air-conditioning system can be calculated as in Equation (4):

$$
\dot{\mathrm{W}}_{\mathrm{tot}}=\dot{\mathrm{W}}_{p u, c h}+\dot{\mathrm{W}}_{p u, c d}+\dot{\mathrm{W}}_{A H U, F C}+\dot{\mathrm{W}}_{c h}+\dot{\mathrm{W}}_{C T}
$$

In Equation (4), $\dot{\mathrm{W}}_{p u, c h}, \dot{\mathrm{W}}_{p u, c d}, \dot{\mathrm{W}}_{A H U, F C}, \dot{\mathrm{W}}_{c h}$ and $\dot{\mathrm{W}}_{C T}$ are respectively the power load of chilled water pumps, condensing water pumps, air handling units (AHU) or fan coils (FC), chillers and cooling towers. In this study, a system performance factor (SPF) for the entire system can be expressed as Equation (5):

$$
S P F=\frac{\dot{Q}_{e}}{\dot{\mathrm{W}}_{\text {tot }}}
$$

$\dot{Q}_{e}$ is the cooling capacity of the air-conditioning system.

\subsubsection{Exergy Analysis}

Kummel [36] relates the second law to economics. Exergy can be taken as the flow availability of a system that performs the maximum reversible work. Regarding the scope of this study, the kinetic and the potential work can be neglected. Hence, exergy can be expressed as $\mathrm{H}-\mathrm{H}_{0}-\mathrm{T}_{0}\left(\mathrm{~S}-\mathrm{S}_{0}\right)$, where $\mathrm{H}$ is the enthalpy and $S$ is the entropy of the respective states. $T_{0}\left(S-S_{0}\right)$ is the entropy generation term or exergy destruction against the dead state. Sayyaadi and Neiatolahi [19] stated that a more convenient form of the exergy of a flowing system consists of a temperature component and a pressure component $E x=E x^{\triangle T}+E x^{\triangle P}$. In this study the pressure component is neglected. The exergy of an air-conditioning system can be defined to be the maximum useful work attainable from a heat transfer process. Lu and $\mathrm{Wu}[6]$ mentioned that in differential form, exergy can be expressed as in Equation (6):

$$
d E x=d E x^{\Delta T}=d \dot{E} x=\left(\frac{T_{0}-T}{\mathrm{~T}}\right) d \dot{Q}_{e}=\left(\frac{T_{0}-T}{\mathrm{~T}}\right) \dot{m} C_{p} d T
$$

Integrating from the given state $\left(T_{e i}, T_{e o}\right)$ to the dead state $\left(T_{0}\right)$, which is the ambient condition in this study, a general equation for calculating exergy rate $\dot{E} x$ is obtained as in Equation (7):

$$
\dot{E} x=\dot{Q}_{e}\left(\frac{T_{0}}{T_{e i}-T_{e o}} \ln \frac{T_{e i}}{T_{e o}}-1\right)
$$


In Equation (7), $\dot{Q}_{e}$ is the refrigeration effect $(\mathrm{kW}), T_{0}$ is the outdoor temperature (the reference environment temperature), $T_{e i}$ is inlet chiller water temperature and $T_{e o}$ is the outlet chiller water temperature. The thermodynamic second law efficiency (exergy efficiency) can be expressed as Equation (8):

$$
\eta_{\Pi}=\frac{\dot{E} x}{\dot{\mathrm{W}}_{t o t}}
$$

In this study, the total exergy destruction rate is the sum of the general and the 24-h systems, as expressed in Equation (9):

$$
\dot{I}_{t o t}=\dot{I}_{t o t, 24 h}+\dot{I}_{t o t, g e n}
$$

where $\dot{\mathrm{I}}_{t o t, 24 h}=-\dot{E} x_{24 h}+\dot{W}_{c h, 24 h}+\dot{W}_{p u, 24 h}+\dot{W}_{A H U \& F C, 24 h}+\dot{W}_{C T, 24 h}$ and $\dot{\mathrm{I}}_{t o t, g e n}=-\dot{E} x_{g e n}+\dot{W}_{c h, g e n}+$ $\dot{W}_{p u, g e n}+\dot{W}_{A H U \& F C, g e n}+\dot{W}_{C T, g e n} . \dot{I}_{t o t}, \dot{I}_{t o t, 24 h}$ and $\dot{I}_{t o t, g e n}$ are the exergy destruction rate for the total, the 24-h system and the general air-conditioning system, respectively.

\subsubsection{Thermoeconomic Analysis}

The thermoeconomic analysis has to consider the construction cost, amortization, maintenance and electricity consumption. In this study, the total revenue requirement levelization (TRRL) method was applied. In this study, the TRRL method takes into account the estimated total carrying charge, along with assumptions for economic, financial and market input parameters calculated on a yearly basis. Moreover, the non-uniform annual monetary values of the carrying charges, maintenance cost and electricity cost are levelized and converted to an equivalent series of constant payments (annuities) [37].

TRRL can be computed as in Equation (10):

$$
T R R L=C R F \sum_{1}^{n} \frac{T R R_{j}}{\left(1+i_{e f f}\right)^{j}}
$$

In Equation (10), CRF is the capital recovery factor. $T R R_{j}$ is the total revenue requirement in the $j$-th year of system operation, and $i_{\text {eff }}$ is the interest rate (\%). In applying Equation (10), each monetary transaction is assumed to occur at year end. The capital recovery factor $C R F$ is calculated by Equation (11):

$$
C R F=\frac{i_{e f f}\left(1+i_{e f f}\right)^{n}}{\left(1+i_{e f f}\right)^{n}-1}
$$

In Equation (11), $\mathrm{n}$ is the economic lifetime in years. The series of payments of the annual electrical cost $E C_{j}$ can be calculated using Equation (12):

$$
E C_{j}=E C_{0}\left(1+r_{E C}\right)^{j}
$$

In Equation (12), $r_{E C}$ is the constant escalation. The levelized value $E C_{L}$ can then be determined multiplying the first year electricity $\operatorname{cost} E C_{0}(\mathrm{NT})$ by the constant escalation levelization factor (CELF) as Equation (13):

$$
E C_{L}=E C_{0} C E L F=E C_{0} \frac{k_{E C}\left(1-k_{E C}^{n}\right)}{\left(1-k_{E C}\right)} C R F
$$

In Equation (13), $\mathrm{k}_{\mathrm{EC}}=\left(1+\mathrm{r}_{\mathrm{EC}}\right) /\left(1+\mathrm{i}_{\mathrm{eff}}\right)$. The terms $r_{E C}$ and $C R F$ are respectively the annual escalation rate of electricity cost and the capital recovery factor. $E C_{0}$ can be computed by Equation (14):

$$
\mathrm{EC}_{0}=\mathrm{C}_{\text {elect }}\left(E_{p u, c h}+E_{p u, c d}+E_{A H U, F C}+E_{c h}+E_{C T}\right)
$$

In Equation (14), $\mathrm{C}_{\text {elect }}$ is the electricity price per $\mathrm{kWh}$ in Taiwan taken as $3.1 \mathrm{NT} / \mathrm{kWh}$. The total annual electric consumption $(\mathrm{kWh})$ includes that of the chiller water pump $\left(\mathrm{E}_{\mathrm{pu}, \mathrm{ch}}\right)$, condensing water 
pumps $\left(\mathrm{E}_{\mathrm{pu}, \mathrm{cd}}\right)$, air side equipment $\left(\mathrm{E}_{\mathrm{AHU}}, \mathrm{FC}\right)$, such as air handling units (AHU) and fan coils $(\mathrm{FC})$, water chillers $\left(\mathrm{E}_{\mathrm{ch}}\right)$ and cooling towers $\left(\mathrm{E}_{\mathrm{CT}}\right)$.

The levelized annual operating and maintenance costs $\mathrm{OMC}_{\mathrm{L}}$ are given in Equation (15):

$$
O M C_{L}=O M C_{0} C E L F=O M C_{0} \frac{k_{O M C}\left(1-k_{O M C}^{n}\right)}{\left(1-k_{O M C}\right)} C R F
$$

where $k_{O M C}=\frac{1+r_{O M C}}{1+i_{e f f}}$, and the term $r_{O M C}$ is a constant representing the nominal escalation rate for the operating and maintenance costs.

The economic operating lifetime of the system is taken to be 15 years. Therefore, the magnitude of the economic constant, such as $i_{e f f}, r_{O M C}$ and $r_{E C}$ are taken to be $0.02,0.03$ and 0.03 , respectively, in the analysis.

For the air-conditioning system, the annual total revenue requirement levelization (TRRL) is equal to the sum of the carrying charge levelization (CCL), electricity costs levelization (ECL) and operating and maintenance cost levelization (OML), as shown in Equation (16):

$$
T R R L=C C L+E C L+O M C L
$$

The levelized cost rate of the total revenue requirement can be calculated by Equation (17):

$$
\begin{aligned}
& \dot{\mathrm{C}}_{\mathrm{TRRL}}=\dot{C}_{C C L 24 h}+\dot{C}_{E C L 24 h}+\dot{C}_{C C L g e n}+\dot{C}_{E C L g e n}+\dot{C}_{O M L} \\
& =\frac{C C L_{24 h}}{m_{24 h}}+\frac{E C L_{24 h}}{m_{24 h}}+\frac{C C L_{g e n}}{m_{g e n}}+\frac{E C L_{g e n}}{m_{g e n}}+\frac{O M L}{m_{O M}}
\end{aligned}
$$

In Equation (17), $\dot{\mathrm{C}}_{\text {TRRL }}$ is the hourly cost of the total revenue requirement levelization. The hourly rates of CCL and ECL are to be calculated separately for the general and the 24-h systems. The annual operating hours of the $24-\mathrm{h}$ and the general systems, $m_{24 h}$ and $m_{g e n}$, are $8784 \mathrm{~h}$ and $4870 \mathrm{~h}$, respectively, according to the actual operation of the train station.

In this study, the reduction of carbon dioxide $\left(\mathrm{CO}_{2}\right)$ emissions due to energy saving was estimated. The emission of carbon dioxide per kWh of electricity used given by Taipower [38] for the year of 2012 was $0.522 \mathrm{~kg} / \mathrm{kWh}$.

\subsubsection{Empirically-Based Performance Models of Equipment}

The energy performance models of chillers refer to Lee et al. [29] and Jiang and Reddy [30]. The regression models of the chillers and pumps are fitted using data provided by equipment suppliers. These models are used in thermoeconomic and exergy analysis in this study. Prediction of chiller COP refers to the modified Gordon-Ng universal model proposed by Jiang and Reddy [30]. The model considers the refrigerant flow rate that may change the internal entropy production in the compressor. The independent variables of chiller COP are then the cooling load ratio $\dot{Q}_{e} / \dot{Q}_{e(\max )}$, evaporator outlet temperature $T_{e o}$ and condenser inlet water temperature $T_{c i}$. The functional form of the model is shown in Equation (18):

$$
\frac{\mathrm{T}_{e o}}{T_{c i}} \cdot\left(1+\frac{1}{C O P}\right)-1=\left(\beta_{1}+\beta_{2} \cdot \frac{\dot{\mathrm{Q}}_{\mathrm{e}}}{\dot{\mathrm{Q}}_{\mathrm{e}(\max )}}\right) \frac{T_{e o}}{\dot{Q}_{e}}+\beta_{3} \cdot \frac{T_{c i}-T_{e o}}{T_{c i} \cdot \dot{Q}_{e}}+\beta_{4} \cdot \frac{\dot{Q}_{e}}{T_{c i}} \cdot\left(1+\frac{1}{C O P}\right)
$$

In Equation (18), the regression constants $\beta 1-\beta 4$ are determined by regressing the performance data provided by equipment suppliers.

Similarly, the power consumption of chilled water pumps and condensing water pumps $\dot{W}_{p u}$ can be expressed in regression form, as shown in Equation (19): 


$$
\dot{\mathrm{W}}_{p u}=\alpha_{0}+\alpha_{1} \dot{\mathrm{V}}+\alpha_{2} \dot{\mathrm{V}}^{2}+\alpha_{3} \dot{\mathrm{V}}^{3}
$$

The independent variable is only the volumetric flow rate $\dot{V}$, whether of the chilled water or the condensing water. The regression constants $\alpha_{1}-\alpha_{3}$ are determined by regressing the performance data provided by equipment suppliers.

\subsubsection{Multi-Objective Optimization}

The two objective functions studied are the economic and thermodynamic objective functions shown in Equation (20) and Equation (21):

$$
\begin{gathered}
\dot{\mathrm{C}}_{\mathrm{TRRL}}^{*}=\frac{\dot{\mathrm{C}}_{T R R L}-\dot{\mathrm{C}}_{T R R L, \text { min }}}{\dot{\mathrm{C}}_{T R R L, \max }-\dot{\mathrm{C}}_{T R R L, \text { min }}} \\
\dot{\mathrm{I}}_{\mathrm{tot}}^{*}=\frac{\dot{I}_{t o t}-\dot{I}_{t o t, \text { min }}}{\dot{I}_{t o t, \text { max }}-\dot{I}_{t o t, \text { min }}}
\end{gathered}
$$

The multi-objective optimization refers to the method of the Pareto optimal frontier [39]. In Equations (20) and (21), $\dot{\mathrm{C}}_{\mathrm{TRRL}}$,min and $\dot{\mathrm{C}}_{\mathrm{TRRL}, \max }$ are the minimum and maximum values of $\dot{\mathrm{C}}_{\mathrm{TRRL}}$ in the Pareto frontier, similarly for $\dot{I}_{t o t, \text { min }}$ and $\dot{I}_{\text {tot,max }} \cdot \dot{\mathrm{C}}_{\mathrm{TRRL}}=\dot{\mathrm{C}}_{\mathrm{TRRL}, \min }$ and $\dot{\mathrm{I}}_{\text {tot }}=\dot{\mathrm{I}}_{\text {tot,min }}$ correspond to the limits of economic and thermodynamic optimization. When Equations (20) and (21) are separately used in single objective optimization, $\dot{\mathrm{C}}_{\text {TRRL }}^{*}$ and $\dot{\mathrm{I}}_{\text {tot }}^{*}$ would lies between 0 and 1.

In this study, the decision variables of selecting chillers are:

(1) Using screw or centrifugal compressors, constant or variable speed drive.

(2) The operating refrigeration capacity.

(3) The coefficient of performance (COP).

(4) Inlet/outlet chilled water and condensing water temperatures.

(5) The cost of chillers.

Similarly, the decision variables of selecting pumps are:

(1) Pumps with constant speed drive or variable speed drive.

(2) The efficiency of pumps.

(3) The pump pressure and water volumetric flow rate $\left(\mathrm{m}^{-3} \cdot \mathrm{s}^{-1}\right)$.

(4) The cost of pumps.

Three optimization cases are compared to the base case, with the operating parameters described in Tables 1 and 2. The three cases are namely cost consideration (CC), thermodynamic efficiency (TE) and multiple objectives of efficiency and cost (MO). The operation constraints of the 24-h and the general air-conditioning systems are listed in Tables 1 and 2. Constraints of these decision variables are partly the limitations emanating from the technical data of equipment suppliers. For the general system, the total chilled water flow rate is $4032 \mathrm{~kg} / \mathrm{min}$ (equivalent to liters per minute (lpm) for water) and is $1210 \mathrm{~kg} / \mathrm{min}$ for the 24-h system. It is noted that the variable frequency drive (VFD) is applied to the chillers and pumps in Case TE and Case MO. VFD systems general cost more, but it would better match the cooling demand and the overall operation of the system. 
Table 1. Operating range of the 24-h air-conditioning system. BC, base case; CC, cost consideration; $\mathrm{TE}$, thermodynamic efficiency; MO, multiple objectives.

\begin{tabular}{|c|c|c|c|c|c|}
\hline Item & & BC & $\mathrm{CC}$ & TE & MO \\
\hline \multirow{3}{*}{$\begin{array}{l}\text { 1. } \quad 422-\mathrm{kW} \\
\text { screw chiller }\end{array}$} & Chiller control & $\mathrm{CFD}^{1}$ & CFD & $\mathrm{VFD}^{2}$ & VFD \\
\hline & $\mathrm{COP}$ & $4.16-5.12$ & $3.66-4.30$ & $4.51-5.35$ & $4.36-5.32$ \\
\hline & $\mathrm{COP}_{\mathrm{avg}}$ & 4.52 & 3.88 & 5.13 & 4.91 \\
\hline \multirow{3}{*}{$\begin{array}{l}\text { 2. Zone chiller pump } \\
\text { water head }(\mathrm{kPa}): 440\end{array}$} & Pump control & CFD & CFD & VFD & VFD \\
\hline & Flowrate (lpm) & 1210 & 1210 & $726-1210$ & $726-1210$ \\
\hline & Efficiency $\eta$ & 0.75 & 0.7 & $0.72-0.75$ & $0.71-0.73$ \\
\hline \multirow{3}{*}{$\begin{array}{l}\text { 3. Condenser pump } \\
\text { water head }(\mathrm{kPa}): 350\end{array}$} & Pump control & CFD & CFD & VFD & VFD \\
\hline & Flowrate (lpm) & 1512 & 1512 & $907-1512$ & 907-1512 \\
\hline & Efficiency $\eta$ & 0.75 & 0.7 & $0.72-0.75$ & $0.71-0.73$ \\
\hline \multicolumn{6}{|c|}{ Chiller operating at $T_{c i}\left({ }^{\circ} \mathrm{C}\right): 26-30 ; T_{c o}\left({ }^{\circ} \mathrm{C}\right): 29-37 ; T_{e i}\left({ }^{\circ} \mathrm{C}\right): 9.8-12.5 ; T_{e o}\left({ }^{\circ} \mathrm{C}\right): 6.5-7.5$} \\
\hline
\end{tabular}

Table 2. Operating range of the general air-conditioning system.

\begin{tabular}{|c|c|c|c|c|c|}
\hline Item & & BC & $\mathrm{CC}$ & TE & MO \\
\hline \multirow{3}{*}{$\begin{array}{l}\text { 1. } 2110-\mathrm{kW} \\
\text { centrifugal chillers }\end{array}$} & Chiller control & $\mathrm{CFD}^{1}$ & CFD & VFD $^{2}$ & CFD \\
\hline & COP & $4.6-6.5$ & $4.52-5.70$ & $5.12-7.27$ & $4.80-6.67$ \\
\hline & $\mathrm{COP}_{\mathrm{avg}}$ & 5.84 & 5.24 & 6.39 & 5.89 \\
\hline \multirow{3}{*}{$\begin{array}{l}\text { 2. Primary chiller pumps } \\
\text { water head }(\mathrm{kPa}): 190\end{array}$} & Pump control & CFD & CFD & VFD & VFD \\
\hline & Flowrate (lpm) & 4032 & 4032 & 2419-4032 & 2419-4032 \\
\hline & Efficiency $\eta$ & 0.77 & 0.72 & $0.73-0.77$ & $0.72-0.75$ \\
\hline \multirow{3}{*}{$\begin{array}{l}\text { 3. Zone } 1 \text { chiller pumps } \\
\text { water head }(\mathrm{kPa}): 370\end{array}$} & Pump control & VFD & CFD & VFD & VFD \\
\hline & Flowrate (lpm) & $2612-4354$ & 4354 & $2612-4354$ & $2612-4354$ \\
\hline & Efficiency $\eta$ & 0.81 & 0.76 & $0.77-0.81$ & $0.75-0.80$ \\
\hline \multirow{3}{*}{$\begin{array}{l}\text { 4. Zone } 2 \text { chiller pump } \\
\text { water head }(\mathrm{kPa}): 270\end{array}$} & Pump control & VFD & CFD & VFD & VFD \\
\hline & Flowrate(lpm) & 1019-1693 & 1693 & 1019-1693 & 1019-1693 \\
\hline & Efficiency $\eta$ & $0.72-0.75$ & 0.7 & $0.72-0.75$ & $0.71-0.74$ \\
\hline \multirow{3}{*}{$\begin{array}{l}\text { 5. Condenser pumps } \\
\text { water head }(\mathrm{kPa}): 385\end{array}$} & Pump control & CFD & CFD & VFD & VFD \\
\hline & Flowrate (lpm) & 7560 & 7560 & $4356-7560$ & $4356-7560$ \\
\hline & Efficiency $\eta$ & 0.84 & 0.79 & $0.81-0.84$ & $0.80-0.83$ \\
\hline \multicolumn{6}{|c|}{ Chiller operating at $T_{c i}\left({ }^{\circ} \mathrm{C}\right): 26-30 ; T_{c o}\left({ }^{\circ} \mathrm{C}\right): 29-37 ; T_{e i}\left({ }^{\circ} \mathrm{C}\right): 9.1-12.5 ; T_{e o}\left({ }^{\circ} \mathrm{C}\right): 6.5-15.7$} \\
\hline
\end{tabular}

\section{Results}

\subsection{Electricity Consumption and Electricity Cost of the Underground Train Station}

The electricity use of an underground train station is vastly different from a commercial building. The train station studied would begin operation at 4:30 A.M. with the general air-conditioning system started at about 6:30 A.M. The hourly monitored power use of the station (the base case (BC)) is presented in Figure 3. Figure 3 shows that for summer months, the peak power occurs in the afternoon of the day. The monthly electricity cost of the underground station is presented in Figure 4 , which clearly indicates that the peak power use of air-conditioning happens in the summer months. It is then obvious that air-conditioning constituted a significant part of the total electricity cost of the underground train station and is also the major cause of the peak power load. 


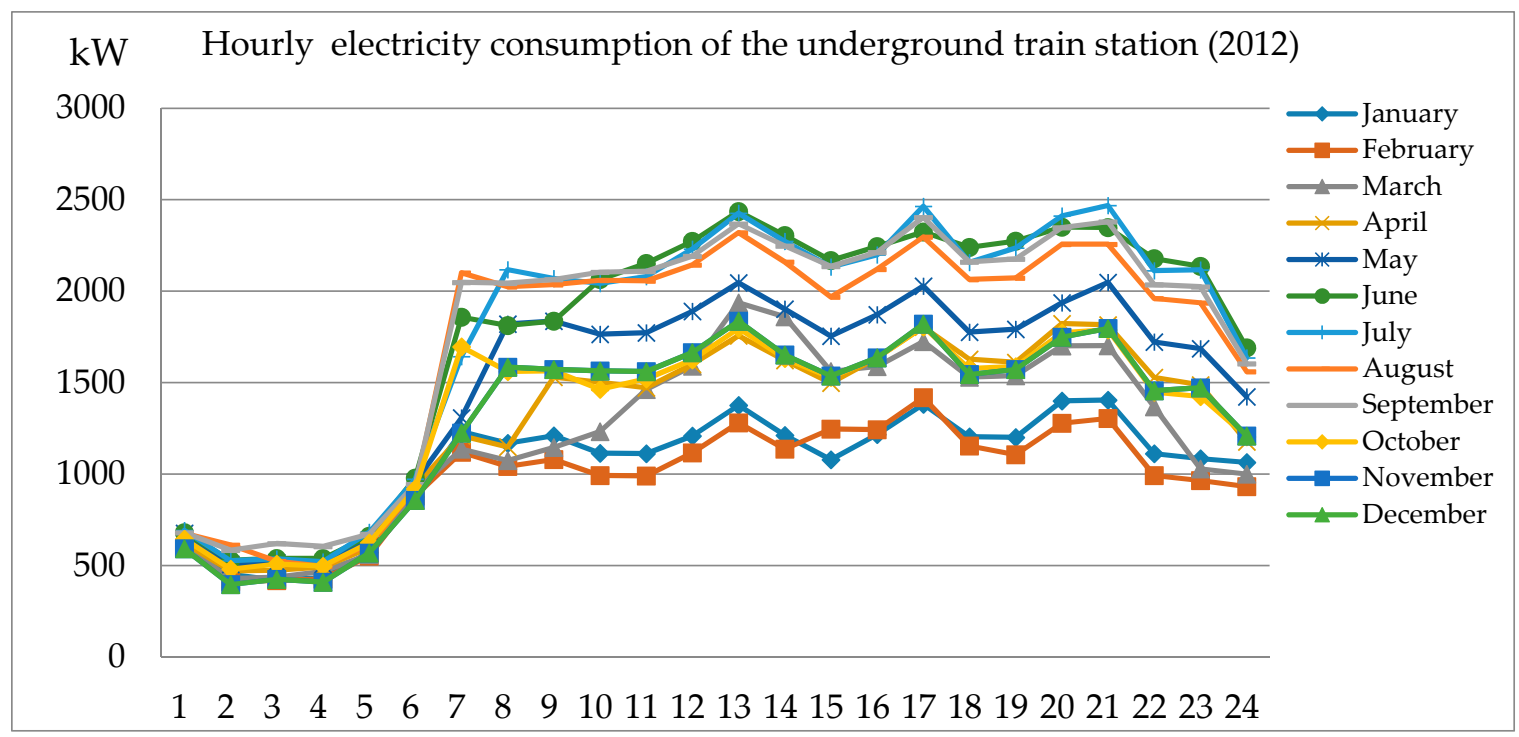

Figure 3. Hourly electricity consumption of the underground train station in 2012.

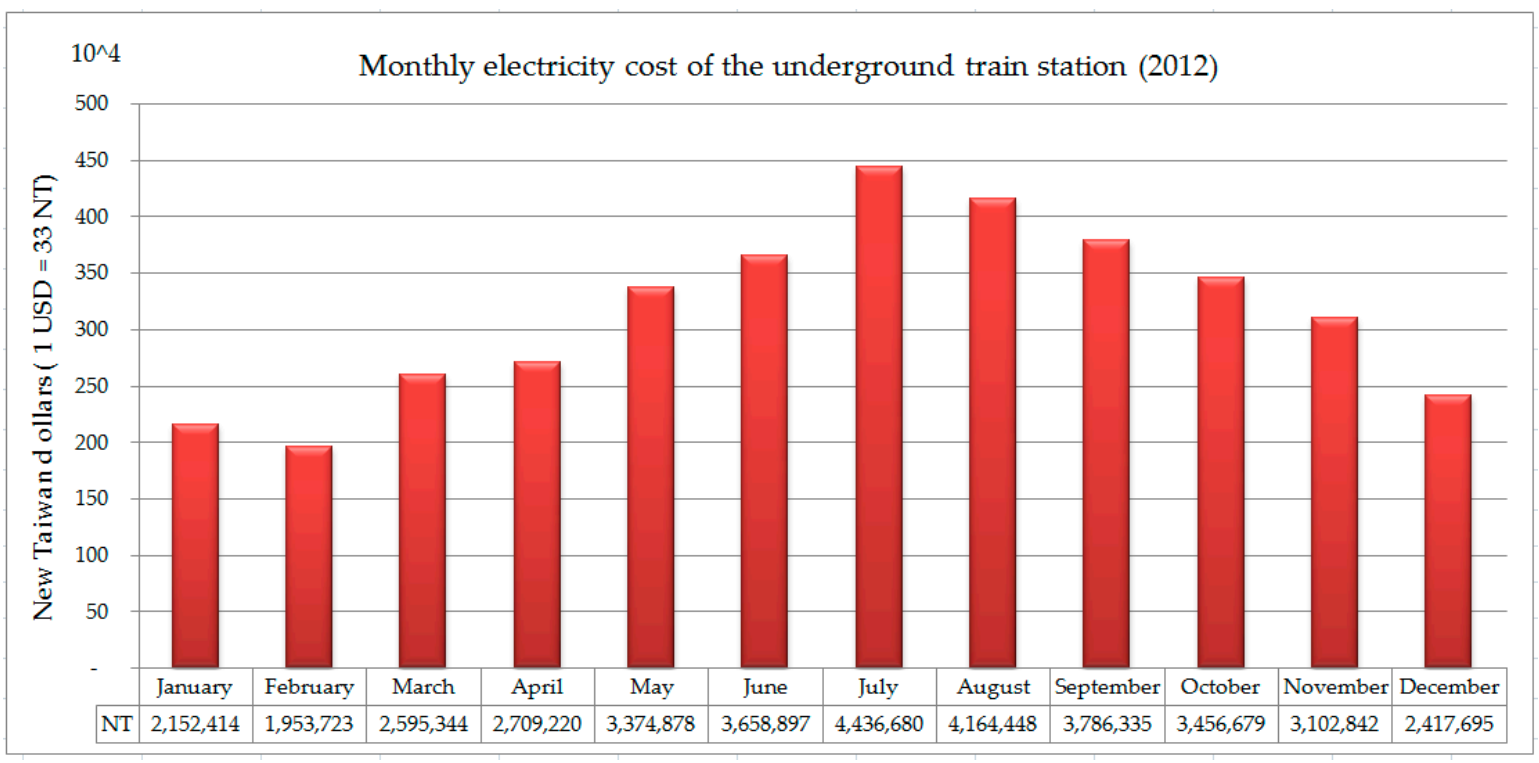

Figure 4. Monthly electricity cost of the underground train station in 2012.

\subsection{Refrigerating Energy and Exergy of Underground Train Station}

The hourly refrigerating capacity of the air-conditioning system is calculated using Equation (1) for each operating hour. The daily cooling load is shown in Figure 5. The 24-h air-conditioning system appears to have an almost constant load through the year. The general system has high peak demand in summer months. The daily refrigeration exergy is determined from Equation (7). The computed results are shown in Figure 6. The chilled water temperature $T_{e}$ in Equation (6) is from the monitored data of the station. The ambient temperature $T_{0}$ was obtained from the Central Weather Bureau of Taiwan [40].

Comparing the results in Figures 5 and 6 it is noted that exergy is about one tenth of the refrigeration effect indicating that the ideal COP of a chiller would be larger than 10, significantly higher than commercial products. The chiller's performance used in this study is presented in Tables 1 and 2. 


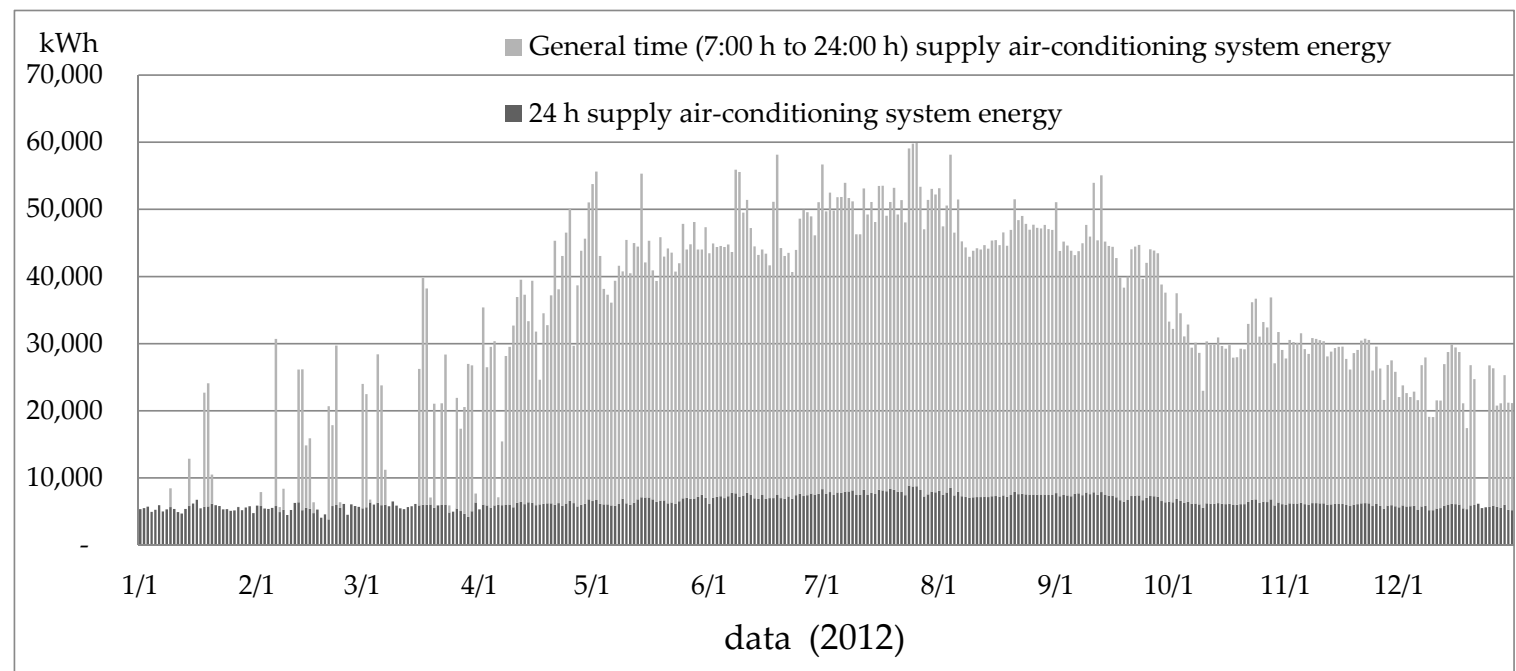

Figure 5. Daily cooling load of the underground train station under study.

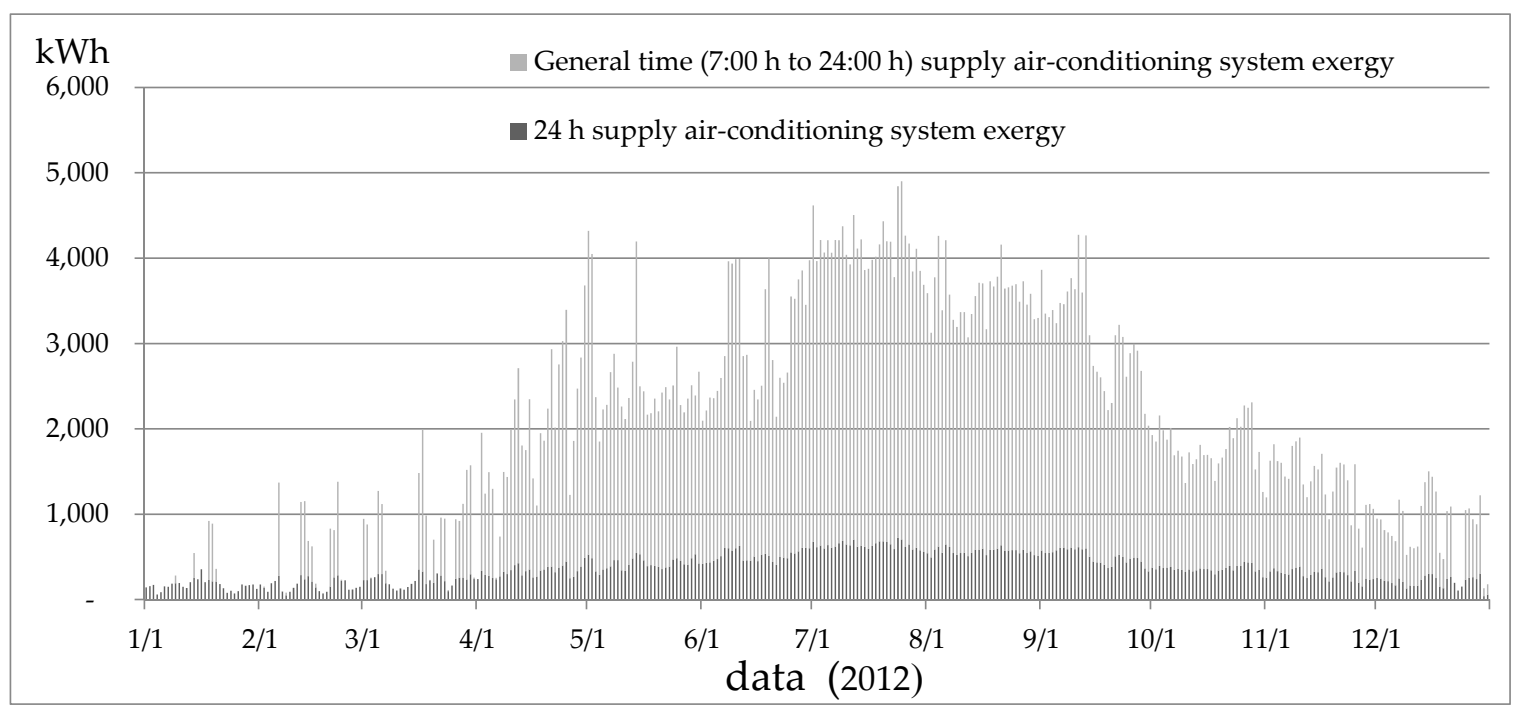

Figure 6. Daily refrigerating exergy of the underground train station under study in 2012.

The monthly average COP of the chillers computed is shown in Figure 7. Chillers of the general air-conditioning system are shown to have higher COP. Larger capacity centrifugal chillers normally are more energy efficient. However, the average COP is significantly less than that obtained from the above exergy analysis. It is also noted that Case TE has the highest average COP followed by Case $\mathrm{MO}$, with Case CC having the lowest average COP.

The annual energy consumption of pumps calculated from the performance models is shown in Tables 3 and 4 . The performance models for each of the optimization cases are based on the pump energy efficiency shown in Tables 1 and 2. Case TE has the lowest pump energy consumption followed by Case MO. Case CC has the highest energy consumption as lower energy efficiency pumps are used. 


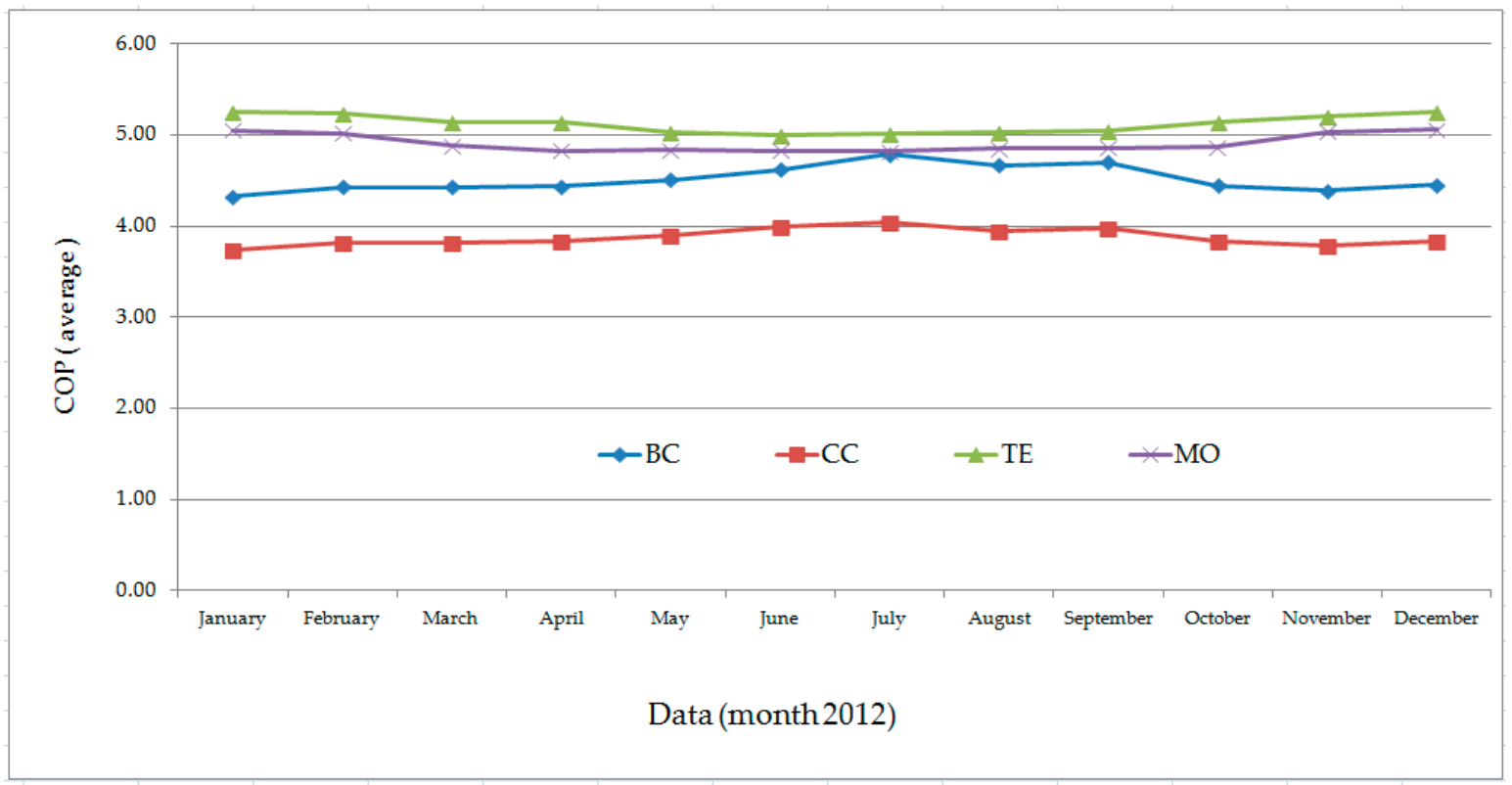

(a)

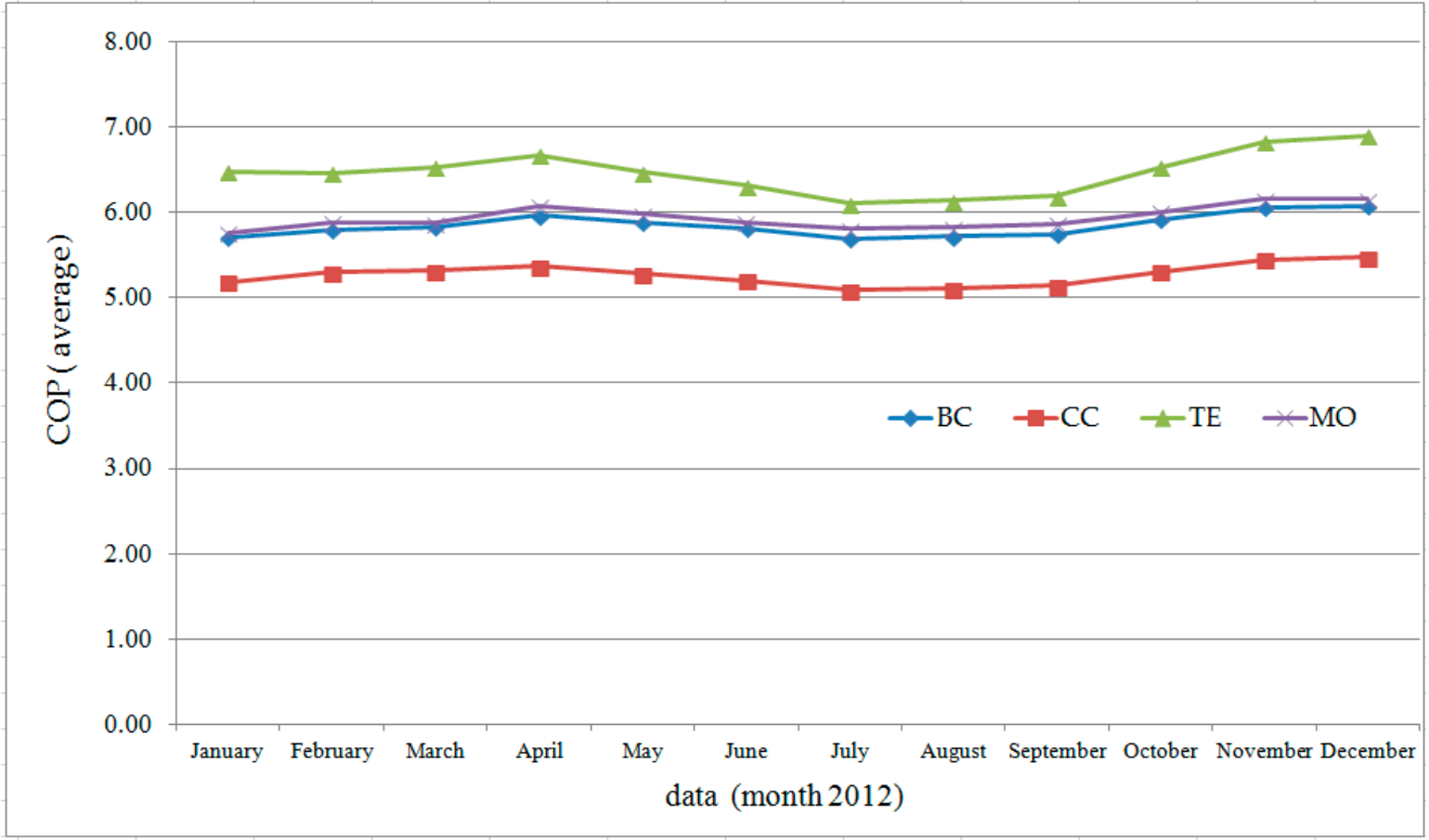

(b)

Figure 7. The monthly average COP of the chillers. (a) The 24-h air-conditioning system; (b) the general air-conditioning system.

Table 3. Energy consumption of the pumps for the 24-h system.

\begin{tabular}{ccccc}
\hline Item & BC & CC & TE & MO \\
\hline Condenser water pump $(\mathrm{kWh})$ & 86,748 & 93,034 & 63,746 & 71,654 \\
Chilled water pump $(\mathrm{kWh})$ & 108,255 & 116,333 & 66,916 & 80,259 \\
Total (kWh) & 195,003 & 209,367 & 130,662 & 151,912 \\
\hline
\end{tabular}


Table 4. Energy consumption of pumps for the general system.

\begin{tabular}{ccccc}
\hline Item & BC & CC & TE & MO \\
\hline Condenser pump (kWh) & 417,128 & 443,867 & 368,903 & 389,143 \\
Primary chilled water pump $(\mathrm{kWh})$ & 118,344 & 126,563 & 105,474 & 111,168 \\
Zone 1 Pump (kWh) & 216,224 & 248,865 & 216,224 & 225,037 \\
Zone 2 Pump (kWh) & 63,941 & 77,676 & 63,941 & 67,649 \\
Total (kWh) & 815,637 & 896,971 & 754,542 & 792,998 \\
\hline
\end{tabular}

Table 5 shows the annual energy use of the air-conditioning systems. Pump energy is the second largest item of energy use. This is the characteristics of an underground train station as long pipelines are needed to deliver chilled water and condensing water. The air side equipment, such as AHU and FC, are not optimized in this study, nor are the cooling towers. It is also noted in Table 5 that chillers make up about half of the total energy use.

Table 5. Annual energy use of the major components of the air-conditioning system.

\begin{tabular}{ccccc}
\hline Electric Energy Use Items (kWh) & BC & CC & TE & MO \\
\hline 24-h system chillers & 521,201 & 607,417 & 480,118 & 527,682 \\
General system chillers & $1,601,799$ & $1,785,079$ & $1,464,479$ & $1,588,376$ \\
24-h pumps & 195,003 & 209,367 & 130,662 & 151,912 \\
General system pumps & 815,637 & 896,971 & 754,542 & 792,998 \\
AHU and FC & 949,551 & 949,551 & 949,551 & 949,551 \\
Cooling towers & 126,607 & 126,607 & 126,607 & 126,607 \\
Total system & $4,209,798$ & $4,574,991$ & $3,905,959$ & $4,137,126$ \\
\hline
\end{tabular}

The monthly average SPF and the second law efficiency of the air-conditioning system are shown in Figure 8. The results are computed using the monitored data of the underground train station in 2012. It can be seen in Figure 8 that SPF is higher than 2.5 for most of the months. The results indicate one unit of energy input would have more than 2.5 units of refrigeration effect. SPF is calculated using Equation (5). The second law efficiency of the system was evaluated using Equation (8).

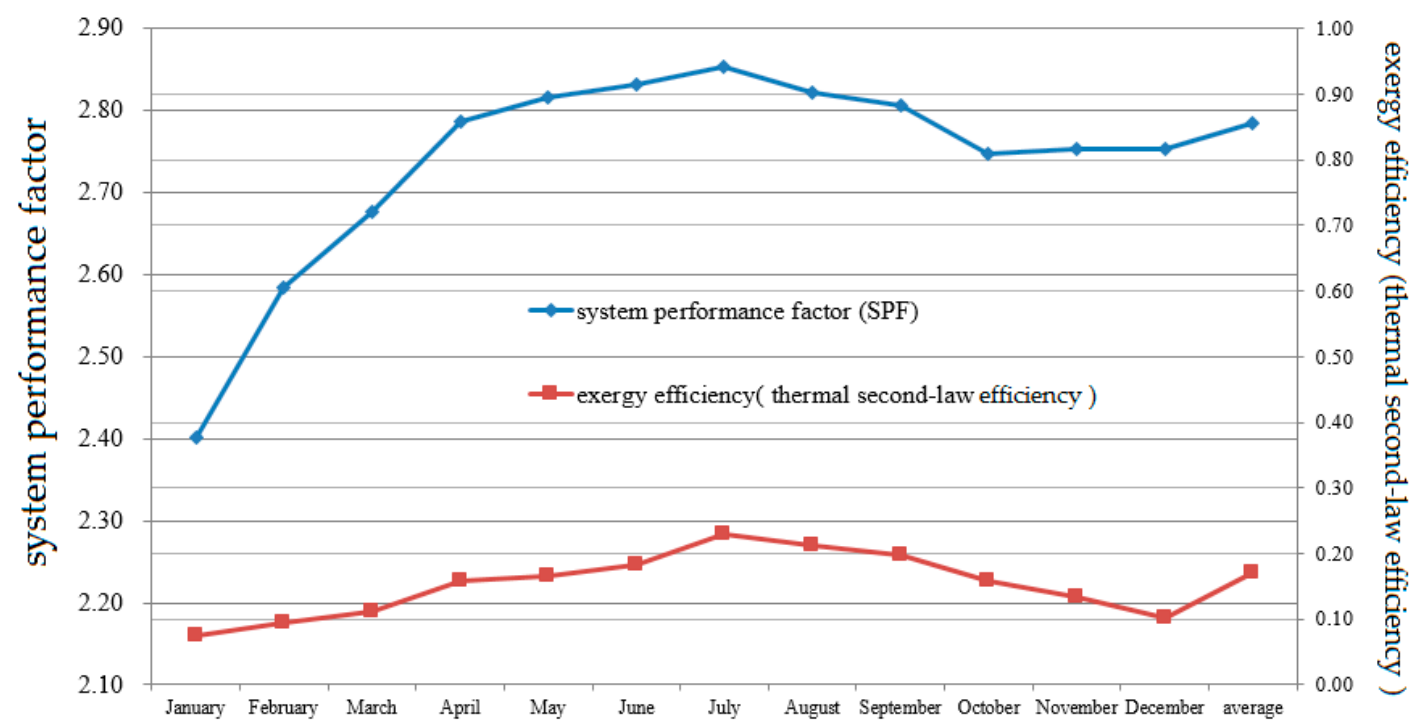

Figure 8. The monthly system performance factor and second law efficiency.

The second law efficiency (efficiency of exergy) is evaluated against the maximum useful work. Therefore, the second law efficiency has a maximum value of 1.0. It can be seen in Figure 8 that the 
second law efficiency is lower than 0.3. In related works found in the research literature, the second law efficiency was evaluated for each component of the air-conditioning system and mostly calculated for ideal cycle operation. In this study, the actual operation of the entire system is evaluated for either SPF or the second law efficiency.

\subsection{Multi-Objective Optimization}

In this study, the multi-objective functions are the normalized total revenue requirement levelization $\dot{\mathrm{C}}_{\mathrm{TRRL}}^{*}$ and the normalized exergy destruction $\dot{\mathrm{I}}_{\mathrm{tot}}^{*}$. The method of the Pareto optimal frontier [39] is applied to obtain the normalized $\dot{\mathrm{C}}_{\mathrm{TRRL}}^{*}$ and $\dot{\mathrm{I}}_{\text {tot }}^{*}$. The normalized $\dot{\mathrm{C}}_{\mathrm{TRRL}}^{*}$ and $\dot{\mathrm{I}}_{\text {tot }}^{*}$ of the four cases are shown in Table 6.

Table 6. $\dot{\mathrm{C}}_{\text {TRRL }}$ and $\dot{I}_{\text {tot }}$ and their optimized normalized values.

\begin{tabular}{ccccc}
\hline Item & $\dot{\mathbf{C}}_{\text {TRRL }}$ & $\dot{\mathbf{I}}_{\text {tot }}$ & $\dot{\mathbf{C}}_{\text {TRRL }}^{*}$ & $\dot{\mathbf{I}}_{\text {tot }}^{*}$ \\
\hline Base case (BC) & 4371 & 646 & 0.21 & 0.44 \\
Cost consideration (CC) & 4338 & 712 & 0 & 1 \\
Thermodynamic efficiency (TE) & 4492 & 594 & 1 & 0 \\
Multiple objectives, cost and efficiency (MO) & 4378 & 626 & 0.26 & 0.27 \\
\hline
\end{tabular}

Figure 9 presents the normalized form of the Pareto optimal frontier in the multi-objective optimization (MO). In Figure 9, multi-objective optimization is at the lowest point of the root mean squares of $\dot{\mathrm{C}}_{\mathrm{TRRL}}^{*}$ and $\dot{\mathrm{I}}_{\text {tot }}^{*}$. For Case MO optimal $\dot{\mathrm{C}}_{\mathrm{TRRL}}^{*}$ is calculated to be about 0.27 and $\dot{\mathrm{I}}_{\text {tot }}^{*}$ at about 0.26. Figure 9 also shows that better cost benefits can be obtained when $\dot{C}_{\text {TRRL }}^{*}$ is lower than 0.26 and better thermodynamics when $\dot{\mathrm{C}}_{\mathrm{TRRL}}^{*}$ is higher than 0.26 . It is noted in Table 6 that for Case MO, $\dot{\mathrm{C}}_{\mathrm{TRRL}}^{*}$ equals 0.26 , as compared to that of Case BC at 0.21 . However, $\dot{\mathrm{I}}_{\text {tot }}^{*}$ of Case MO is significantly lower than that of Case BC.

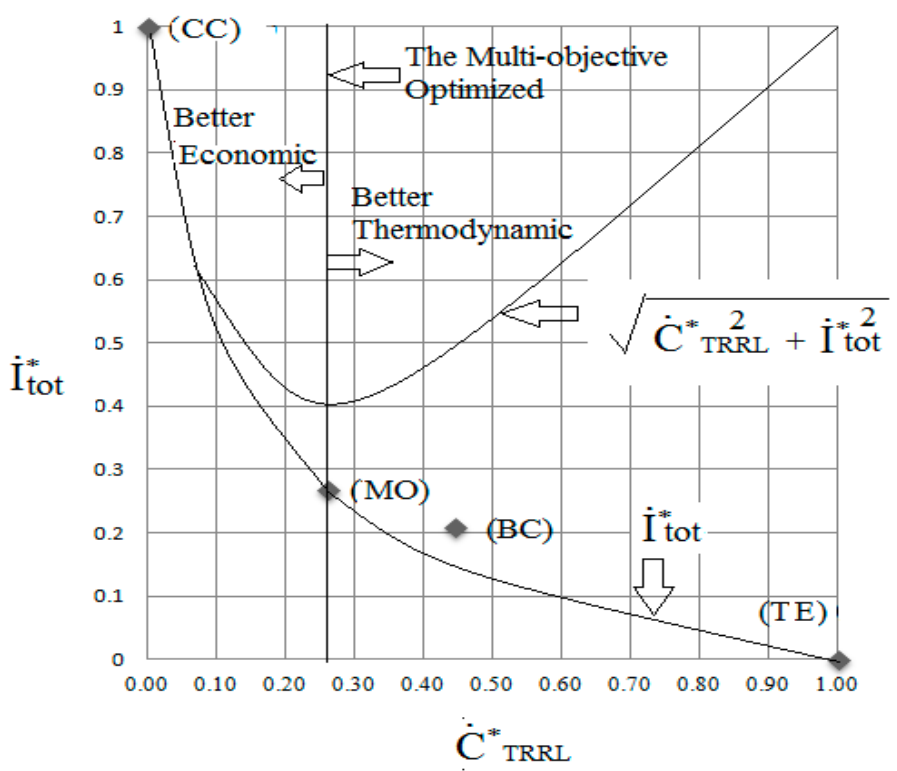

Figure 9. The normalized Pareto optimal frontier.

\subsection{Energy Exergy and Thermoeconomic Analysis}

The results presented in Table 7 are reevaluated for an economic lifetime of 15 years. For the Case CC, in order to lower the initial construction cost, lower energy efficiency equipment is selected. Consequently, Case CC has the highest electricity cost, the lowest exergy efficiency, the lowest system 
performance factor (SPF) and the highest $\mathrm{CO}_{2}$ emission. At the same time, Case $\mathrm{CC}$ has the lowest carrying charge rate and the lowest total revenue requirement levelized rate. In comparison, when thermodynamic efficiency is the sole concern (Case TE), the highest system performance and exergy efficiency are obtained. However, Case TE has the highest total revenue requirement levelized rate. For the case of multi-objective optimization (Case MO), a balance of cost and efficiency is the concern. The results show that the construction cost of MO is slightly higher than the base case (BC), but would result in a system performance factor (SPF) and second law efficiency (exergy efficiency) next to Case TE. It is also noted that Case BC, compared to Case TE and Case MO, has higher electricity consumption, lower SPF and higher annual $\mathrm{CO}_{2}$ emission. It is known that Case $\mathrm{BC}$ was designed for energy saving. However, when exergy and thermodynamic analysis is applied for further analysis, $\mathrm{BC}$ is not an optimal design.

Table 7. Energy exergy and thermoeconomic analysis of the air-conditioning system.

\begin{tabular}{lcccc}
\hline Item & BC & CC & TE & MO \\
\hline Air-conditioning system construction cost (NT) & $136,001,250$ & $130,156,950$ & $144,767,700$ & $138,527,235$ \\
Electricity levelized cost rate (NT/h) & 1797 & 1957 & 1670 & 1733 \\
Maintenance levelized cost rate (NT/h) & 562 & 455 & 680 & 517 \\
Carrying charge levelized cost rate (NT/h) & 2012 & 1926 & 2142 & 2058 \\
Total revenue requirement levelized cost rate (NT/h) & 4371 & 4338 & 4492 & 4378 \\
Total exergy destruction rate (kW) & 647 & 712 & 594 & 626 \\
Total refrigeration effect $(\mathrm{kWh} / \mathrm{y})$ & $11,719,265$ & $11,719,265$ & $11,719,265$ & $11,719,265$ \\
Total refrigeration exergy (kWh/y) & 722,226 & 717,814 & 722,925 & 722,627 \\
Total electricity consumption(kWh/y) & $4,209,798$ & $4,574,991$ & $3,905,959$ & $4,094,428$ \\
CO ${ }_{2}$ emission (kg/y) & $2,197,514$ & $2,388,145$ & $2,038,910$ & $2,137,291$ \\
System performance factor (SPF) & 2.78 & 2.56 & 3.00 & 2.83 \\
Exergy efficiency (thermal second-law efficiency) & 0.172 & 0.157 & 0.185 & 0.175 \\
\hline
\end{tabular}

The comparison of the exergy destruction $\dot{I}_{t o t}$ for the components of the air-conditioning system is shown in Figure 10. The chiller is the largest item of exergy destruction, followed by pumps and air side equipment. As the air side components are not included in the analysis, the exergy destruction of AHU and FC is the same for the four cases. The main reason that air side equipment is not included in the evaluation is due to the uncertainty in the monitored data. When the entire system is concerned, Case CC has exergy destruction significantly higher than all other cases. When cost and energy saving are both considered, Case MO is superior to Case BC in terms of exergy destruction.

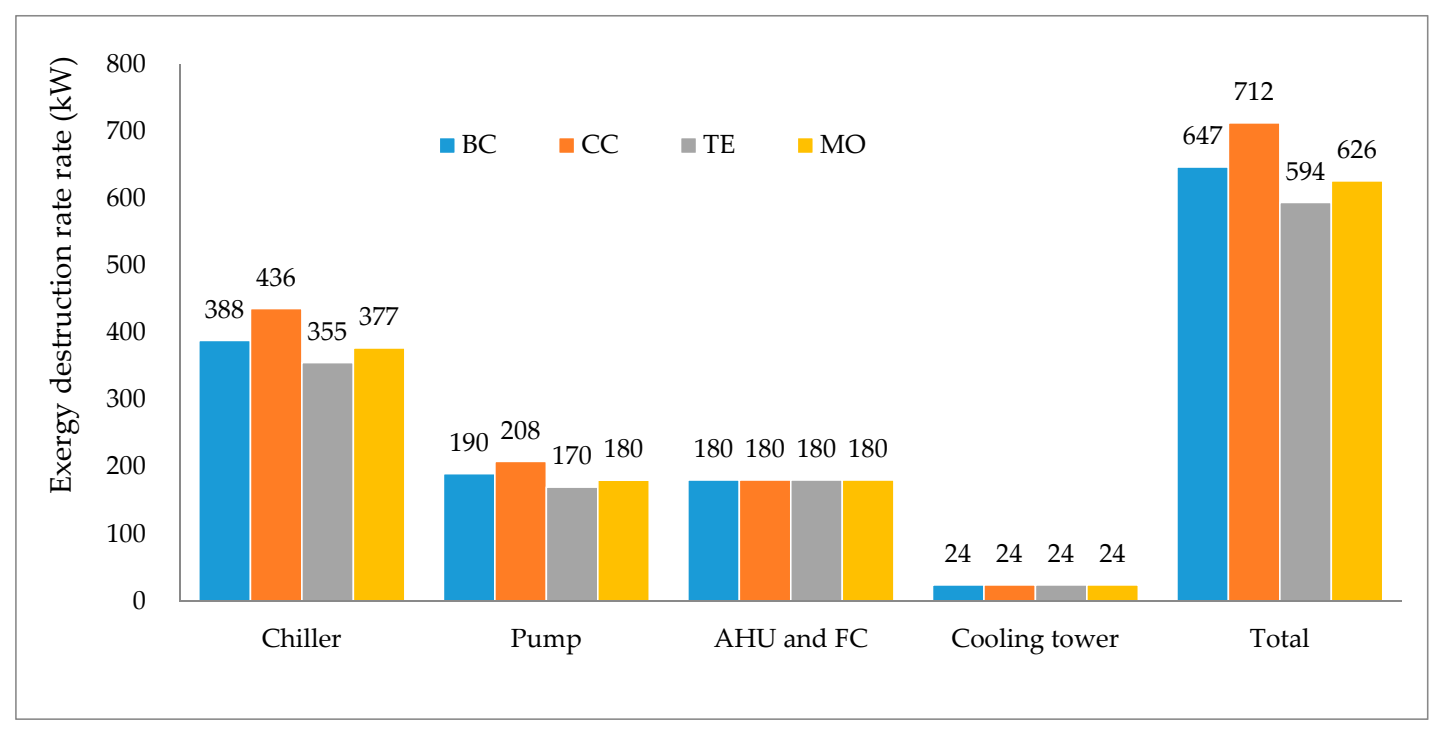

Figure 10. Exergy destruction of the air-conditioning system. 
The comparison of the levelized cost rate is shown in Figure 11. Case CC has the lowest carrying charge cost rate due to the lower construction cost, but has significantly higher electricity cost over the other cases. When the total revenue requirement levelized cost rate is compared, Case CC is less than Case $\mathrm{BC}$ by $33 \mathrm{NT} / \mathrm{h}$. Case $\mathrm{MO}$ has a total revenue requirement levelized cost rate slightly higher than Case BC, but has a lower electricity cost rate. In comparison, Case TE has the highest total revenue requirement levelized cost rate.

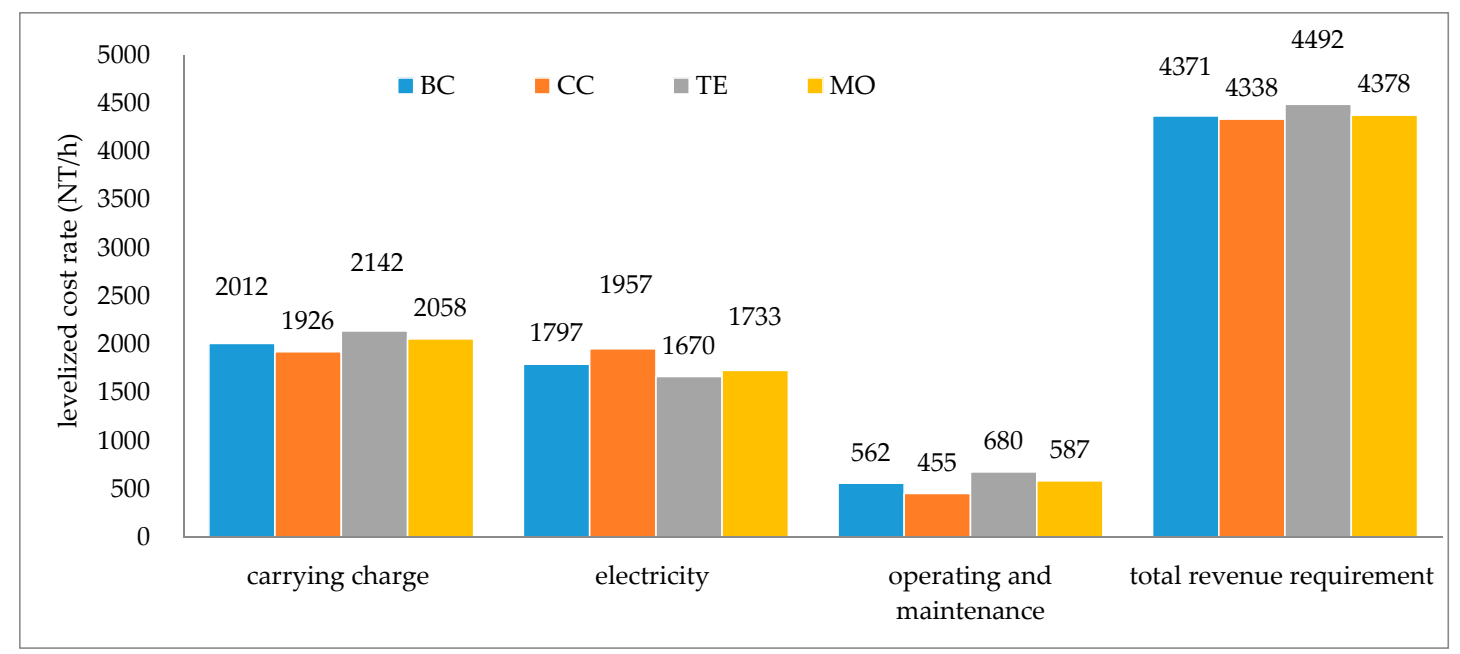

Figure 11. Levelized costs rate for the four cases.

Figure 12 shows the percentage comparison of construction cost, total exergy destruction rate, total revenue requirement levelized cost rate and $\mathrm{CO}_{2}$ emission. Case $\mathrm{BC}$ is taken to be $100 \%$ in all of the items. The construction cost of Case CC is $95.7 \%$, but is $99.24 \%$ in terms of $\dot{C}_{T R R L}$. The result shows that Case CC may not be a good selection. Case TE is the best selection in terms of reducing $\mathrm{CO}_{2}$ emission and low exergy destruction. However, Case TE has $\dot{C}_{T R R L} 2.76 \%$ higher than that of Case $\mathrm{BC}$. The comparison shows that Case TE is a good selection when reducing $\mathrm{CO}_{2}$ emission is a prime concern. Case $\mathrm{MO}$ has $\dot{C}_{T R R L}$ almost as an equal percentage as for Case BC, but has lower exergy destruction and lower $\mathrm{CO}_{2}$ emission. Case $\mathrm{MO}$ appears to be a superior selection when economics and second law efficiency are both a concern.

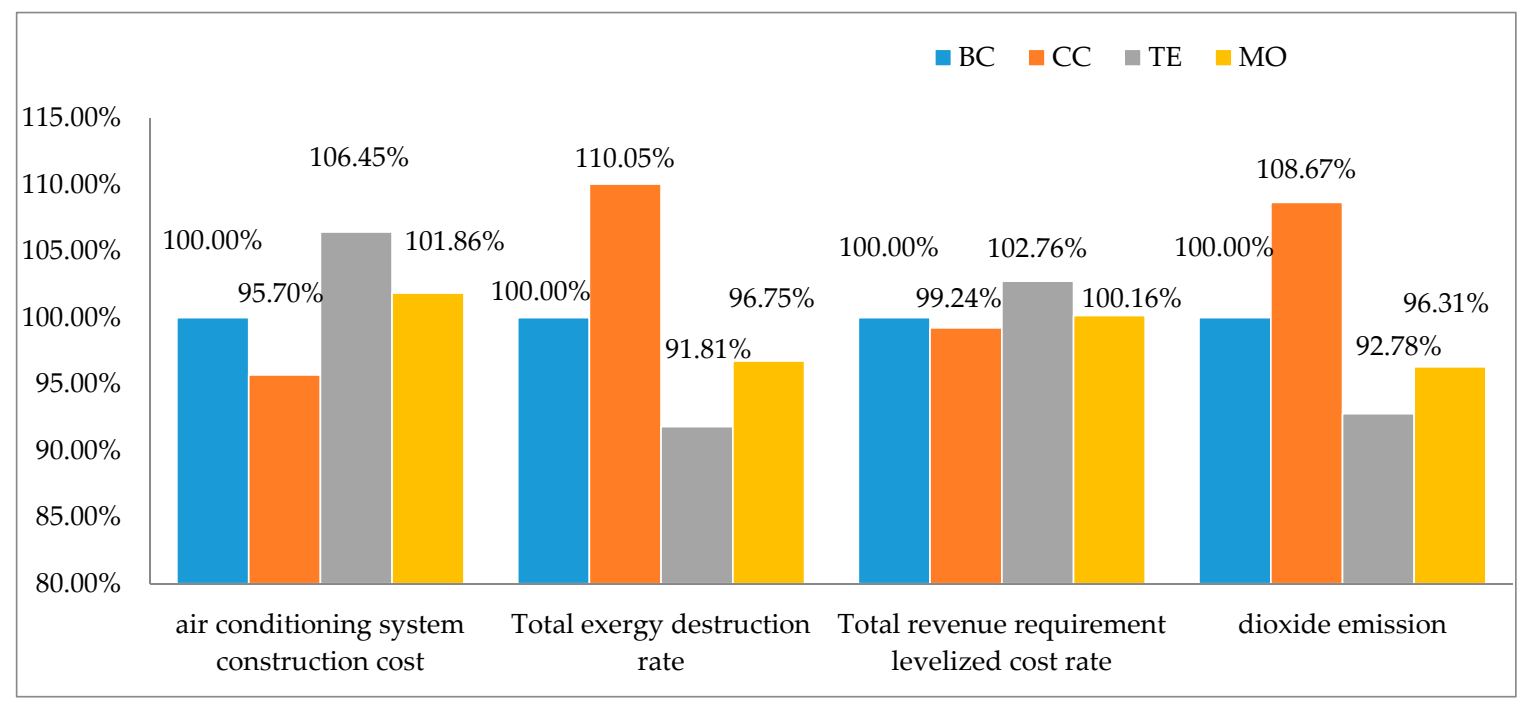

Figure 12. Percentage comparison of the four cases. 


\section{Discussion}

The above results show that applying exergy and thermoeconomic analysis to the air-conditioning system design would be of practical importance. It is also noted that when the total revenue requirement levelized cost rate is evaluated, a lower construction cost may not result in good economics. Optimization of multiple objectives would provide a balanced consideration of both energy efficiency and investment return. Case $\mathrm{MO}$ has a total revenue requirement levelized cost rate comparable to Case $\mathrm{BC}$, but performs better in reducing $\mathrm{CO}_{2}$ emission and low exergy destruction.

The results obtained also show that both the system performance factor (SPF) and second law efficiency can be applied to the entire air-conditioning system. The results of exergy efficiency analysis as given in Table 7 show that system exergy efficiency is lower than 0.2 in all four cases. The results indicate high potential for further improvement in equipment efficiency. SPF is an effective indicator of the system performance. For Case TE, SPF equals about 3.0; this means one unit of electrical energy input would result in about three units of refrigeration effect in energy terms.

\section{Conclusions}

It has been shown that thermoeconomic and exergy analysis can be used to improve the energy performance and cost savings of the air-conditioning system of an underground train station. It is also shown that lower initial construction cost may have only a marginal benefit when the total revenue requirement levelized rate is evaluated. Optimization of thermodynamic efficiency would bring the benefits of a lower exergy destruction rate and lower energy use. The results also show that multi-objective optimization has the benefit of a lower total revenue requirement levelized rate, but performs well in reducing $\mathrm{CO}_{2}$ emission and low exergy destruction. The annual system exergy efficiency obtained is lower than 0.2 , which points to high potential in equipment efficiency improvement. A system performance factor is introduced to evaluate the efficiency of the entire air-conditioning system. In summary, this study shows that thermoeconomic and exergy analysis can be applied in an annual analysis, so as to achieve optimized hourly operation of an air-conditioning system in general and for an underground train station in particular. Moreover, it has been shown that a higher system performance factor (SPF) can be achieved along with lower annual $\mathrm{CO}_{2}$ emission.

Acknowledgments: This research is supported by the Ministry of Science and Technology of Taiwan with research Project MOST 103-2221-E-027-110, and this is gratefully acknowledged hereby. Comments from the reviewers and the editorial office help to improve the paper and are also acknowledged hereby.

Author Contributions: Ke Yang Liao performed the analysis. Yew Khoy Chuah contributed in the presentation of the results and partly the writing of the paper.

Conflicts of Interest: The authors declare no conflict of interest.

\section{Nomenclature}

$\begin{array}{ll}\text { CCL } & \text { Carrying charge levelization }(\mathrm{NT} / \mathrm{y}) \\ \mathrm{CELF} & \text { Constant escalation levelization factor } \\ \mathrm{COP} & \text { Coefficient of performance } \\ \mathrm{CRF} & \text { Capital recovery factor } \\ \dot{C}_{T R R L} & \text { Total revenue requirement levelized cost rate }(\mathrm{NT} / \mathrm{h}) \\ \dot{\mathrm{C}}_{\mathrm{TRRL}}^{*} & \text { Normalized form of } \dot{C}_{T R R L} \\ \mathrm{EC} & \text { Electrical cost }(\mathrm{NT}) \\ \mathrm{Ex} & \text { Exergy }(\mathrm{kWh}) \\ \mathrm{H} & \text { Enthalpy }(\mathrm{kWh}) \\ \dot{I}_{\text {tot }} & \text { Total exergy destruction rate }(\mathrm{kW}) \\ \dot{\mathrm{I}}_{\text {tot }}^{*} & \text { Normalized form of } \dot{I}_{\text {tot }} \\ \mathrm{K}_{\mathrm{EC}} & \text { The constant of electricity cost }(\text { Equation }(13))\end{array}$


NT

OMC

$\dot{Q}$

Q

$S$

SPF

$\mathrm{U}$

TCR

TRRL

W

\section{Greek symbols}

$\eta$

$\eta_{\Pi}$

i

\section{Subscripts and superscripts}

ac

AHU

$\mathrm{cd}$

CT

e

elect

FC

$i$

j

$k$

$\mathrm{m}$

$\mathrm{n}$

o

$\mathrm{pu}$

tot
New Taiwan dollars, 1 USD $=33$ NT

Operating and maintenance cost (NT/y)

Cooling capacity $(\mathrm{kW})$

Heat transfer $(\mathrm{kWh})$

Entropy $(\mathrm{kWh} / \mathrm{K})$

System performance factor

Internal energy $(\mathrm{kWh})$

Total capital recovery

Total revenue requirement levelization

Power $(\mathrm{kW})$

\section{Efficiency}

The thermodynamic second law efficiency (the efficiency of exergy) The volume flowrate $\left(\mathrm{m}^{3} \cdot \mathrm{s}^{-1}\right)$

\section{References}

1. Fu, Q.S. Thermodynamic Analysis Method in Energy System; Xi'an Jiaotong University Press: Xi'an, China, 2005; Chapter 15.

2. Kodal, A.; Sahin, B.; Yilmaz, T. Effects of internal irreversibility and heat leakage on the finite time thermoeconomic performance of refrigerators and heat pumps. Energy Convers. Manag. 2000, 41, 607-619. [CrossRef]

3. Kodal, A.; Sahin, B.; Oktem, A.S. Performance analysis of two stage combined heat pump system based on thermoeconomic optimization criterion. Energy Convers. Manag. 2000, 41, 1989-1998. [CrossRef]

4. Yumrutas, R.; Kunduz, M.; Kanoglu, M. Exergy analysis of vapor compression refrigeration systems. Exergy Int. J. 2002, 2, 266-272. [CrossRef]

5. Rezaie, B.; Dincer, I.; Esmailzadeh, E. Exergy options for residential buildings assessment. Energy Convers. Manag. 2013, 65, 637-647. [CrossRef]

6. Lu, S.; Wu, J.Y. Optiomal selection among different domestic energy consumption patterns based on energy and exergy analysis. Energy Convers. Manag. 2010, 51, 1398-1406. [CrossRef]

7. Marletta, L. Air condition systems from a 2nd law perspective. Entropy 2010, 12, 859-877. [CrossRef] 
8. Yilmaz, M.; Sara, O.N.; Karsli, S. Performance evaluation criteria for heat exchangers based on second law analysis. Exergy Int. J. 2001, 1, 278-294. [CrossRef]

9. Bejan, A. Thermodynamic optimization of geometry in engineering flow systems. Exergy Int. J. 2001, 1, 269-277. [CrossRef]

10. Bisio, G.; Rubatto, G. Work and production aspects of irreversible processes in closed and steady-state open systems. Exergy Int. J. 2002, 2, 192-205. [CrossRef]

11. Chen, L.G.; Li, Y.; Sun, F.R.; Wu, C. Optimal performance of an irreversible absorption refrigerator. Exergy Int. J. 2002, 2, 167-172. [CrossRef]

12. Wall, G.; Gong, M. On exergy and sustainable development-Part 1: Conditions and concepts. Exergy Int. J. 2001, 1, 128-145. [CrossRef]

13. Abhilash, S.; Pradeep, A.; Gyuwan, K.; Dong, K.H. Thermodynamic analysis of inlet air cooling system for a centrifugal compressor. In Proceedings of the 7th International Exergy, Energy and Environment Symposium, Valenciennes, France, 27-30 April 2015; C12.

14. Sciubba, E. Beyond thermoeconomics? The concept of Extended Exergy Accounting and its application to the analysis and design of thermal systems. Exergy Int. J. 2001, 1, 68-84. [CrossRef]

15. Li, H.R.; Braun, J.E. Economic Evaluation of Benefits Associated with Automated Fault Detectionand Diagnosis in Rooftop Air Conditioners. ASHRAE Trans. 2007, 113, 200-210.

16. Sivasakthivel, T.; Murugesan, K.; Thomas, H.R. Optimization of operating parameters of ground source heat pump system for space heating and cooling by Taguchi method and utility concept. Appl. Energy 2014, 116, 76-85. [CrossRef]

17. Liu, X.P.; Niu, J.L. An optimal design analysis method for heat recovery devices in building Applications. Appl. Energy 2014, 129, 364-372. [CrossRef]

18. Piacentino, A.; Talamo, M. Innovative thermoeconomic diagnosis of multiple faults in air conditioning units: Methodological improvements and increased reliability of results. Int. J. Refrig. 2013, 36, 2343-2365. [CrossRef]

19. Sayyaadi, H.; Neiatolahi, M. Multi-objective optimization of a cooling tower assisted vapor compression refrigeration. Int. J. Refrig. 2013, 34, 243-256. [CrossRef]

20. Sayyaadi, H.; Neiatolahi, M. Multi-objective optimization of a cooling tower assisted ground source heat pump. Geothermics 2011, 40, 221-232.

21. Sun, T.Q.; Wang, X.H.; Ma, X.G. Relationship between the economic cost and the reliability of the electric power supply system in city: A case in Shanghai of China. Appl. Energy 2009, 86, 2262-2267. [CrossRef]

22. Rosen, M.A. Exergy and economics: Is exergy profitable? Exergy Int. J. 2002, 2, 218-220. [CrossRef]

23. Aminyavari, M.; Najafi, B.; Shirazi, A.; Rinaldi, F. Exergetic, economic and environmental (3E) analyses, and multi-objective optimization of a $\mathrm{CO}_{2} / \mathrm{NH}_{3}$ refrigeration system. Appl. Energy 2014, 65, 42-50. [CrossRef]

24. Mamaghani, A.H.; Najafi, B.; Shirazi, A.; Rinaldi, F. 4E analysis and multi-objective optimization of an integrated MCFC (molten carbonate fuel cell) and ORC (organic Rankine cycle) system. Energy 2015, 82, 650-663. [CrossRef]

25. Mansureh, K.; Rahim, K.S.; Keyvan, B. Muti-objective optimization of power and heat in a combined gas turbine and organic Rankine cycle. In Proceedings of the 7th International Exergy, Energy and Environment Symposium, Valenciennes, France, 27-30 April 2015; C15.

26. Keyvan, B.; Rahim, K.S. Thermoeconomic muti-objective optimization of an ammonia-water power/cooling cycle coupled with a HCCI engine. In Proceedings of the 7th International Exergy, Energy and Environment Symposium, Valenciennes, France, 27-30 April 2015; C30.

27. Hanifi, K.; Javaherdeh, K.; Yari, M. Exergy and exergoeconomic analysis and optimization of the cogeneration cycle under solar radiation dynamic model using genetic algorithm. In Proceedings of the 7th International Exergy, Energy and Environment Symposium, Valenciennes, France, 27-30 April 2015; C41.

28. Lee, K.P.; Cheng, T.A. A simulation-optimization approach for energy efficiency of chilled water system. Energy Build. 2012, 54, 290-296. [CrossRef]

29. Lee, T.S.; Liao, K.Y.; Lu, W.C. Evaluation of the suitability of empirically-based models for predicting energy performance of centrifugal water chillers with variable chilled water flow. Appl. Energy 2012, 93, 583-595. [CrossRef]

30. Jiang, W.; Reddy, T.A. Reevaluation of the Gordon-Ng performance models for water-cooled chillers. ASHRAE Trans. 2003, 109, 272-287. 
31. Tirmizi, S.A.; Gandhidasan, P.; Zubair, S.M. Performance analysis of a chilled water system with various pumping schemes. Appl. Energy 2012, 100, 238-248. [CrossRef]

32. Ma, Z.J.; Wang, S.W.; Xu, X.H.; Xiao, F. A supervisory control strategy for building cooling water systems for practical and real time applications. Energy Convers. Manag. 2008, 49, 2324-2336. [CrossRef]

33. Du, Z.; Jin, X.; Fan, B. Evaluation of operation and control in HVAC (heating, ventilation and air conditioning) system using exergy analysis method. Energy 2015, 89, 372-381. [CrossRef]

34. Mohammadi, S.M.H.; Ameri, M. Energy and exergy comparison of a cascade air conditioning system using different cooling strategies. Int. J. Refrig. 2013, 41, 14-26. [CrossRef]

35. Zago, M.; Casalegono, A.; Marchesi, R.; Rinaldi, F. Efficiency analysis of independent and centralized heating systems for residential buildings in northern Italy. Energies 2011, 4, 2115-2131. [CrossRef]

36. Kummel, R. The Second Law of Economics: Energy, Entropy, and the Origins of Wealth; Springer: New York, NY, USA, 2011; pp. 100-102.

37. Bejan, A.; Tsatsaronis, G.; Morran, M. Thermal Design and Optimization; Wiley: New York, NY, USA, 1996.

38. Taiwan Power Company, Jan. to Dec. Taiwan Railway Administration Songshan Station Electricity Price List (1 January 2012-31 December 2012). Available online: http:/ /www.taipower.com.tw/ (accessed on 29 March 2014).

39. Konak, A.; Coit, D.W.; Smith, A.E. Multi-objective optimization using genetic algorithms: A tutorial. Reliab. Eng. Syst. Saf. 2006, 91, 992-1007. [CrossRef]

40. Central Weather Bureau. Taipei Outdoor Temperature (1 January 2012-31 December 2012). Available online: http:/ / www.cwb.gov.tw/V7/observe/real/46692.htm (accessed on 24 April 2014).

(C) 2016 by the authors; licensee MDPI, Basel, Switzerland. This article is an open access article distributed under the terms and conditions of the Creative Commons by Attribution (CC-BY) license (http:/ / creativecommons.org/licenses/by/4.0/). 